\title{
Proteinuria in Chronic Kidney Disease and its Management
}

\author{
Ahmed SS ${ }^{1}$, Laila $\mathrm{TR}^{2}$, Begum $\mathrm{HA}^{3}$, Moniruzzaman ${ }^{4}$
}

\begin{abstract}
Proteinuria is a marker of kidney damage and an important risk factor for progression of chronic kidney disease as well as cardiovascular morbidity and mortality. Albumin is the principal component of proteinuria in glomerular disease. The presence of persistent albumin in the urine is a clear sign of glomerular abnormality. Microalbuminuria describes the urinary excretion of small amounts of albumin which identifies the very early stage of diabetic kidney disease. The albumin creatinine ratio is the preferred method of detecting microalbuminuria. There is strong evidence that treatment in the early stages of chronic kidney disease reduces progression of kidney damage. The levels of proteinuria in both diabetic and non-diabetic kidney disease at which management should be addressed have been reviewed. This article also reviews the interventions recommended for early stages of chronic kidney disease to reduce the risk of progression to end stage kidney failure. Angiotensin converting enzyme inhibitors and angiotensin 2 receptor blockers are more effective in reducing proteinuria and retarding the progression of kidney disease in comparison to other therapies which lower systemic blood pressure to a similar degree.
\end{abstract}

Keywords: chronic kidney disease, diabetic kidney disease, proteinuria, microalbuminuria, macroalbuminuria

\section{Introduction}

Persistent proteinuria usually indicates kidney disease and is recognized as a risk factor for atherosclerosis with cardiovascular morbidity and mortality ${ }^{1-3}$. Normally less than $150 \mathrm{mg} /$ day of protein appears in urine, and a proportion of that is Tamm-Horsfall protein which is secreted by the tubules ${ }^{1}$. Occasionally, proteinuria occurs only during the day, and the first morning sample is

\footnotetext{
1. Corresponding Author:

Professor Dr. Sheikh Salahuddin Ahmed MBBS, FCPS

Professor \& Head of Department of Medicine

Bangladesh Institute of Health Sciences, Mirpur-1, Dhaka

Email: drsksalahahmed@yahoo.com

2. Dr. Tarafdar Runa Laila MBBS, FCPS, MS

Assistant Professor, Department of Obs \& Gyne

Bangabandhu Sheikh Mujib Medical University, Dhaka

3. Dr. Hosne Ara Begum MBBS, DDV, FCPS

Associate Professor, Department of Dermatology \& Venereology Bangladesh Institute of Research and Rehabilitation for Diabetes Endocrine and Metabolic Disorders, Shahbag, Dhaka

4. Moniruzzaman MPhil (NCD)

Senior Research Fellow

Department of Community Medicine

Bangladesh University of Health Sciences Dhaka, Bangladesh
}

negative; such 'orthostatic proteinuria' is usually regarded as benign. It is important to consider other causes of increased albumin excretion. Relatively minor leakage of albumin into the urine may occur transiently after vigorous exercise, during fever or urinary tract infection, menstrual contamination, vaginal discharge and in intercurrent illness ${ }^{4}$. Tests should be repeated once the stimulus is no longer present. Other causes include diabetic and non-diabetic renal disease (including various forms of glomerulonephritis), uncontrolled hypertension, heart failure and pre-eclampsia during pregnancy ${ }^{5}$.

Dipstick test for urine albumin provides a simple semiquantitative test. The lower limit of detection for urinary protein using dipsticks or reagent strips is $300 \mathrm{mg} / \mathrm{L}^{6}$. By reagent strip a reading greater than 'trace' indicates significant proteinuria ${ }^{6}$. However, urinary albumin excretion (UAE) rates as low as $30 \mathrm{mg} /$ day can be detected using radioimmunoassay techniques ${ }^{6}$. The albumin: creatinine ratio (ACR) is a useful surrogate marker for proteinuria and is used instead of the 24 hour urine collection for quantification of protein excretion. At significant levels of glomerular dysfunction, albumin accounts for $70 \%$ of serum protein, so ACR values are a little lower than comparable protein: creatinine ratio (PCR) values ${ }^{1}$. Positive dipstick tests should be confirmed in the laboratory by measuring either the ACR or PCR preferably on an early morning urine sample ${ }^{5}$. An early morning urine sample is preferred because studies have shown that it correlates best with 24 hour protein excretion, and an early morning sample is required for the diagnosis of orthostatic proteinuria ${ }^{5}$. Where a first void specimen is not possible or practicable, a random urine specimen is acceptable ${ }^{5,7}$. The ACR or PCR in a random urine specimen has replaced protein excretion in a 24 hour collection as the preferred method for measuring proteinuria ${ }^{5,8}$. Twenty four hour timed collections are more burdensome and add little to prediction or accuracy ${ }^{4}$. For low levels of proteinuria, ACR in preferred, as it has far greater sensitivity than PCR and enhances early identification of chronic kidney disease (CKD). ACR is the recommended method for people with diabetes ${ }^{9-12}$. For quantification and monitoring significant levels of proteinuria, PCR can be used as an alternative ${ }^{9}$. Changes in PCR give valuable information about the progression of renal disease ${ }^{1}$.

\section{Microalbuminuria and Macroalbuminuria}

The National Kidney Foundation (NKF), an organization in the United States, defines microalbuminuria as excretion of $30-300 \mathrm{mg}$ of albumin in a 24 hour urine collection sample (equivalent to albumin excretion rate of $20-200 \mu \mathrm{g} / \mathrm{min}$ in a 
timed collection of urine; or ACR 30-300 mg/g without regard to age and sex in a random or spot sample of urine), with values $>300 \mathrm{mg} / 24$ hour being defined as macroalbuminuria ${ }^{13}$. Macroalbuminuria is also known as clinical albuminuria or proteinuria (as it correlates with a urinary protein excretion $0.5 \mathrm{~g} / 24$ hour $)^{5,14}$.

The cut-off values differ a little among guidelines with microalbuminuria being defined as $2.0-20.0 \mathrm{mg} / \mathrm{mmol}$ (men) and 2.8-28.0 (women) in Canada ${ }^{15}, 2.5-30.0 \mathrm{mg} /$ $\mathrm{mmol}$ (men) and 3.5-30.0 mg/mmol (women) in Europe ${ }^{5,16 \text {, }}$ ${ }^{17}$, and 2.5-25.0 $\mathrm{mg} / \mathrm{mmol}$ (men) and 3.5-35.0 (women) in Australia ${ }^{18}$ and macroalbuminuria as $>20 / 28 \mathrm{mg} / \mathrm{mmol}$, > $30 \mathrm{mg} / \mathrm{mmol}$ and $>25 / 35 \mathrm{mg} / \mathrm{mmol}$ respectively. The American Diabetes Association (ADA) has defined microalbuminuria as excretion of 30-299 $\mathrm{mg}$ of albumin in a 24 hour urine collection (equivalent to albumin excretion rate of $20-199 \mu \mathrm{g} / \mathrm{min}$ in a timed collection of urine; or ACR $30-299 \mu \mathrm{g} / \mathrm{mg}$ creatinine in a random or spot sample of urine irrespective of sex), with values $\geq 300 \mathrm{mg} / 24$ hour being defined as macroalbuminuria ${ }^{14}$. Therefore the normal rate of albumin excretion in diabetes will be $<30 \mathrm{mg} / 24$ hours. The National Institute for Health and Clinical Excellence (NICE) guideline defines microalbuminuria as ACR 2.5 to $25.0 \mathrm{mg} / \mathrm{mmol}$ in men and ACR 3.5 to 35 $\mathrm{mg} / \mathrm{mmol}$ in women ${ }^{9}$. The International Diabetes Federation (IDF) considers microalbuminuria ACR $>2.5 \mathrm{mg} / \mathrm{mmol}$ in men, > $3.5 \mathrm{mg} / \mathrm{mmol}$ in women. An ACR > $30 \mathrm{mg} / \mathrm{mmol}$ indicates macroalbuminuria ${ }^{7}$. Microalbuminuria indicates the early stage of diabetic kidney disease ${ }^{6}$.

\section{Significant Proteinuria}

In people without diabetes, significant proteinuria is considered to be present when the urinary protein excretion $0.5 \mathrm{~g} / 24$ hour or more (this is approximately equivalent to ACR $30 \mathrm{mg} / \mathrm{mmol}$ or more or a PCR $50 \mathrm{mg} / \mathrm{mmol}$ or more $)^{9}$. Proteinuria upto $2 \mathrm{~g} / 24$ hour are non-specific and may occur in any type of renal disease. Values greater than this indicate a glomerular abnormality ${ }^{1,6}$. The most common causes are the various forms of glomerulonephritis and diabetic nephropathy ${ }^{6}$. Twenty four hour protein excretion $>3 \mathrm{~g}$ (known as heavy proteinuria) is considered nephrotic range and always indicates glomerular disease 1. Hematuria combined with significant proteinuria usually indicates glomerulonephritis ${ }^{6}$.

\section{Glomerular Filtration Rate (GFR)}

In addition to the assessment of urinary albumin excretion, assessment of glomerular function is important in patients with kidney disease ${ }^{14}$. The GFR is the best measure of overall kidney function. The normal level of GFR varies according to age, sex, and body size. In persons 30 years or younger, the normal GFR is approximately $125 \mathrm{ml} / \mathrm{min}$ per $1.73 \mathrm{~m}^{2}$ and declines by approximately $1 \mathrm{ml} / \mathrm{min}$ per 1.73 $\mathrm{m}^{2}$ per year thereafter ${ }^{19}$. A GFR level less than $60 \mathrm{~mL} / \mathrm{min}$ per $1.73 \mathrm{~m}^{2}$ represents loss of half or more of the adult level of normal kidney function ${ }^{20-22}$. This GFR level also corresponds with a serum creatinine concentration higher than $1.5 \mathrm{mg}$ per $\mathrm{dL}(132.6 \mu \mathrm{mol}$ per $\mathrm{L})$ in men and higher than $1.3 \mathrm{mg}$ per $\mathrm{dL}(114.9 \mu \mathrm{mol}$ per $\mathrm{L})$ in women ${ }^{11,12}$. At GFR below $60 \mathrm{~mL} / \mathrm{min}$, the prevalence of complications of CKD increases ${ }^{20-22}$. However in people aged over 70 years, an estimated GFR (eGFR) in the range $45-59 \mathrm{ml} / \mathrm{min} / 1.73$ $\mathrm{m}^{2}$, if stable over time and without any other evidence of kidney damage, is unlikely to be associated with CKDrelated complications ${ }^{9}$.

\section{Definition of Chronic Kidney Disease}

The NKF defines CKD as either kidney damage or decreased kidney function for 3 or more months ${ }^{19}$. The definition of CKD is the same, regardless of age and sex. This definition is widely accepted and has been adopted in

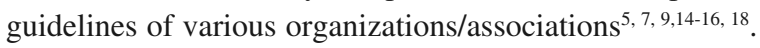
Decreased kidney function means a GFR of less than $60 \mathrm{~mL}$ per minute per $1.73 \mathrm{~m}^{2}$ body surface area ${ }^{19}$. A GFR rate of more than $60 \mathrm{~mL} / \mathrm{min} / 1.73 \mathrm{~m}^{2}$ is considered abnormal if it is accompanied by documented evidences of kidney damage. Evidence of kidney damage includes abnormalities in urine sediment, abnormalities in blood and urine biochemistry, or abnormal findings on imaging studies ${ }^{19}$. Therefore stages 3-5 may be defined by GFR alone (GFR $<60 \mathrm{~mL} / \mathrm{min}$ ), whereas stages 1 and 2 (GFR $60 \mathrm{~mL} / \mathrm{min}$ or more) also require the presence of persistent proteinuria, albuminuria, hematuria, pathological or structural renal abnormalities 9 . CKD also can be defined by the presence of urinary albumin in an excretion rate higher than $300 \mathrm{mg}$ per 24 hours or urinary ACR $30 \mathrm{mg} / \mathrm{mmol}$ or more, or PCR 50 $\mathrm{mg} / \mathrm{mmol}$ or more (approximately equivalent to urinary protein excretion $0.5 \mathrm{~g} / 24$ hours or more $)^{7,9,19,23}$.

\section{Diabetic Kidney Disease (DKD)}

The term DKD refers to a presumptive diagnosis of kidney disease caused by diabetes ${ }^{13}$. In diabetes, CKD is diagnosed on the basis of a raised urine albumin or a reduced glomerular filtration rate or GFR $\left(<60 \mathrm{ml} / \mathrm{min} / 1.73 \mathrm{~m}^{2}\right)^{7}$. Microalbuminuria indicates the early stage of $\mathrm{DKD}^{6}$. In the absence of another identifiable or treatable cause of kidney disease, patients with diabetes and CKD should be treated as if they have $\mathrm{DKD}^{13}$. DKD traditionally termed "diabetic nephropathy," is a clinical diagnosis that historically has been based on the findings of albuminuria with no other cause, in a person with diabetes ${ }^{13}$. The term diabetic glomerulopathy should be reserved for biopsy-proven kidney disease caused by diabetes ${ }^{13}$. In most individuals the diagnosis of DKD is made clinically, as biopsy may not alter management of such patient ${ }^{24}$. However a kidney biopsy may be required in some patients with diabetes and CKD to 
determine the underlying cause; and referral to a physician experienced in the care of kidney disease should be considered when there is uncertainty about the etiology of kidney disease (patients having heavy proteinuria, hematuria, active urine sediment, absence of retinopathy, rapid decline in GFR, resistant hypertension) ${ }^{4}$.

ACR is the recommended method for the detection of albuminuria in people with diabetes ${ }^{5,7,9,13-16,18}$. Dipsticks test is negative for microalbuminuria ${ }^{1}$. Because significant renal damage will have occurred before dipstick tests become positive, patients with diabetes mellitus should be screened regularly for microalbuminuria by measurement of the ACR in a random spot collection ${ }^{4}$. The NKF, IDF, ADA and other organizations recommend diabetic patients for yearly screening for microalbuminuria ${ }^{4}, 5,7,13-16,18$. Screening should include measurement of urinary ACR in a spot urine sample, measurement of serum creatinine and calculation of eGFR ${ }^{13}$.

\section{Treatment of Proteinuria in CKD}

a. Proteinuria in diabetes: Treatments that lower urinary albumin excretion may slow the progression of DKD and improve clinical outcomes ${ }^{13}$. Therefore, albuminuria reduction should be considered as treatment target in $\mathrm{DKD}^{13}$. Both angiotensin-converting enzyme (ACE) inhibitors and angiotensin-receptor blockers (ARBs) are effective in reducing protein excretion ${ }^{13,25-29}$. Treatment with an ACE inhibitor or an ARB should be considered even in normotensive people with diabetes and microalbuminuria as they delay the progression from micro- to macroalbuminuria in people with type 2 diabetes ${ }^{9}, 13,17$. Metaanalysis of trials have shown that ACE inhibitors and ARBs can cause microalbuminuria to regress to no albuminuria in diabetes $^{30,31}$. ACE inhibitors and ARBs preferentially lower intra-glomerular pressure and reduce proteinuria ${ }^{23}$. Effective control of blood glucose has been shown to reduce the progression of CKD in people with diabetes ${ }^{13}$. The Diabetes Control and Complications Trial (DCCT) conducted in US, and the United Kingdom Prospective Diabetes Study (UKPDS) have definitively shown that intensive diabetes therapy can significantly reduce the risk of the development of microalbuminuria and overt nephropathy in people with diabetes $^{32,33}$. The half-life of insulin is prolonged in CKD due to reduced tubular metabolism of insulin; insulin requirements may therefore decline in diabetic patients in advanced $\mathrm{CKD}^{13}$.

Both ACE inhibitors and ARBs delay progression from micro- to macro-albuminuria in people with type 2 diabetes and hypertension ${ }^{7}$. In one study, combination therapy with candesartan (ARB) and lisinopril (ACE inhibitor) was found to be more effective than treatment with either drug alone in reducing blood pressure and microalbuminuria in patients with type 2 diabetes, hypertension, and microalbuminuria ${ }^{34}$. In another study, a 300-mg daily dose of irbesartan reduced proteinuria levels and the risk of doubling of serum creatinine level compared with $10 \mathrm{mg}$ daily of amlodipine or placebo in mostly hypertensive people with type 2 diabetes and nephropathy ${ }^{28}$. ARBs have been shown to delay the progression of nephropathy in those who have macroalbuminuria and renal insufficiency (serum creatinine $>1.5 \mathrm{mg} / \mathrm{dl})^{7}$.

b. Proteinuria in hypertension: Management of blood pressure needs to be intensified (target $\leq 130 / 80 \mathrm{mmHg}$ ) ${ }^{7}$. The level of proteinuria at which ACE inhibitors or ARBs should be initiated has also been defined for patients with hypertension. ACE inhibitors or ARBs should be offered to non-diabetic people with CKD and hypertension with a urinary protein excretion $0.5 \mathrm{~g} / 24$ hour or more ${ }^{5,9,10}$. Ample of evidences show that these agents are more effective than other anti-hypertensive drugs in preventing the progression of kidney disease ${ }^{35-41}$. Patients with hypertension with ACR $<30 \mathrm{mg} / \mathrm{mmol}$ ) ACE inhibitor, ARB, long acting calcium channel blocker, thiazide diuretics or beta-blocker can be used $^{9}$.

When ACE-inhibitor therapy is started, some patients with chronic kidney disease may have an initial decrease in GFR (usually less than $10 \mathrm{~mL}$ per minute per $1.73 \mathrm{~m}^{2}$ ), a mild increase in the serum creatinine concentration (less than 20 percent of the baseline value), and a mild increase in the potassium level (usually less than $0.5 \mathrm{mmol}$ per $\mathrm{L})^{42}$. Therefore, in people with CKD, serum creatinine and potassium levels should be measured and the GFR should be estimated before starting ACE inhibitor/ARB therapy. These measurements should be repeated between 1 and 2 weeks after starting ACE inhibitor/ARB therapy and after each dose increase ${ }^{9}$. ACE inhibitor/ARB therapy should not normally be started if the pretreatment serum potassium concentration is significantly above the normal reference range (typically more than $5.0 \mathrm{mmol} / \mathrm{L}$ ) .

\section{c. Proteinuria in patients without hypertension or} diabetes: For patients without hypertension or diabetes, there is insufficient evidence to determine the level of proteinuria at which to initiate therapy with an ACE inhibitor or ARB. (i) However, a large trial showed benefit of ACE-inhibitor treatment compared with conventional antihypertensive treatment among patients with 1 or more gram of proteinuria per day (PCR about $100 \mathrm{mg} / \mathrm{mmol})^{10,43}$, ${ }^{44}$. (ii) It is also established that ACE inhibitor/ARB therapy for people with significant proteinuria (a total urinary protein excretion $0.5 \mathrm{~g} / 24 \mathrm{~h}$ or more) without diabetes is beneficial $^{9}$. (iii) However, it is not yet known whether ACE inhibitor/ARB therapy in people without diabetes and with lower levels of proteinuria in the absence of cardiovascular indications is of additional benefit ${ }^{9}$. There is currently no proven role for screening for microalbuminuria in patients who do not have diabetes ${ }^{5}$. Treatment of other causes of proteinuria e.g. glomerulonephritis should be addressed accordingly (with corticosteroids or cytotoxics or both as indicated).

d. Limitation of dietary protein intake: Studies in patients with varying stages of nephropathy have shown that restriction of dietary protein helps slow the progression of 
albuminuria, GFR decline, and occurrence of end-stage kidney disease (ESKD) ${ }^{45,}$. . Dietary protein restriction should be considered particularly in patients whose nephropathy seems to be progressing despite optimal glucose and blood pressure control and use of ACE inhibitor and/or $\mathrm{ARBs}^{46}$. The IDF recommends limiting protein intake to $1 \mathrm{~g} / \mathrm{kg}$ daily if proteinuria ${ }^{7}$. The ADA recommends reduction of protein intake to $0.8-1.0 \mathrm{~g} / \mathrm{kg}$ body $\mathrm{wt} /$ day in individuals with diabetes and the earlier stages of CKD and to $0.8 \mathrm{~g} / \mathrm{kg}$ body wt/day in the later stages of CKD that may improve measures of renal function ${ }^{4}$. Current recommendations from the NKF based on evidence from animal studies suggest a protein intake of 0.8 to $1.0 \mathrm{~g}$ per $\mathrm{kg}$ per day and a daily caloric intake of 30 to $35 \mathrm{kcal}$ per $\mathrm{kg}$ per day in patients with chronic kidney disease ${ }^{19}$.

e. Other approaches: Microalbuminuria is a well-established marker of increased cardiovascular risk ${ }^{5,7,9,13-16,18,47}$. Aspirin therapy (75-162 mg/day) is considered as a primary prevention strategy in those with diabetes at increased cardiovascular risk which also includes most men $>50$ years of age or women $>60$ years of age who have albuminuria 4 . Severe proteinuria may lower the plasma albumin concentration to reduce the plasma oncotic pressure and cause generalized edema warranting diuretic therapy. Dyslipidemia is a primary risk factor for cardiovascular disease and a common complication of progressive kidney disease ${ }^{13,48}$. In response to low oncotic pressure produced by hypo-albuminemia, there is a nonspecific increase of lipid synthesis by liver, the dyslipidemia produced needs treatment by lipid modifying drugs ${ }^{1}$. Smoking is a strong risk factor for cardiovascular mortality in patients at risk for CKD. It also is strongly associated with the progression of nephropathy ${ }^{49}$. Smoking cessation should be strongly encouraged at each office visit ${ }^{23}$.

\section{Discussion}

Proteinuria is an important and sensitive marker of kidney damage and a risk factor for progression of CKD as well as cardiovascular morbidity and mortality ${ }^{1-3,5,7,9,13-16,18,42}$. In many types of kidney disease, the severity of proteinuria correlates risk of progressive loss of renal function. Treatment of earlier stages of CKD is effective in slowing the progression toward kidney failure ${ }^{19}$. Treatments that are effective at lowering proteinuria also reduce the risk of progression of kidney disease and its complications ${ }^{13}$. ACE inhibitors and ARBs are more effective at reducing proteinuria and retarding the progression of kidney disease than other therapies which lower systemic blood pressure to a similar degree ${ }^{35-41}$.

Diabetic nephropathy occurs in 20-40\% of patients with diabetes and is the single leading cause of ESKD in western countries ${ }^{4}$. Persistent microalbuminuria in diabetes is an independent risk factor for progression of CKD and development of cardiovascular morbidity and mortality. Therefore there is a general agreement that people with diabetes should be screened regularly to detect early stage of kidney damage and receive treatment ${ }^{7}$. Patients should not be screened during intercurrent illness, infection or an acute metabolic crisis. The best possible metabolic control of diabetes should be achieved before investigating patients for microalbuminuria ${ }^{5}$. The ACR is the preferred method of detecting microalbuminuria. Patients with microalbuminuria who progress to macroalbuminuria ( $\geq 300 \mathrm{mg} / 24 \mathrm{~h}$ ) are likely to progress to ESKD. However, a number of interventions if initiated at early stage have been demonstrated to reduce the risk and slow the progression of kidney disease ${ }^{4}$. GFR decreases relentlessly at rates greater than $10 \mathrm{~mL} / \mathrm{min} / \mathrm{y}$ in those with poorly controlled hypertension and albuminuria, but much more slowly ( 1 to $4 \mathrm{~mL} / \mathrm{min} / \mathrm{y}$ ) in those with effective glycemic and blood pressure control ${ }^{13,50}$. The benefits of ACE inhibitor /ARB therapy for people with diabetes with microalbuminuria and all levels of macroalbuminuria, irrespective of the presence of hypertension or CKD stage, are well established. Treatment initiation with ACE inhibitors or ARBs unless contraindicated in diabetes having persistent microalbuminuria have been strongly recommended.

In all other patients of CKD (without diabetes) having PCR $>50 \mathrm{mg} / \mathrm{mmol}$ (ACR > $30 \mathrm{mg} / \mathrm{mmol}$ ), ACE inhibitors and/or ARBs should be used if tolerated, independently of the presence of hypertension to reduce proteinuria and slow the decline in GFR.

Finally it can be concluded that every diabetic patient should be screened annually for albuminuria preferably by ACR. ACE inhibitors and ARBs reduce albuminuria in CKD and slow the decline in GFR in both diabetic and non-diabetic patients with or without hypertension.

\section{References}

1. Goddard J, Turner AN, Stewart LH. Kidney and urinary tract disease. In: Colledge NR, Walker BR S \& Ralston SH. Davidson's Principle and Practice of Medicine. 21st International ed. Churchill Livingstone Elsevier;2010:480-496

2. Go AS, Chertow GM, Fan D, McCulloch CE, Hsu CY. Chronic kidney disease and the risks of death, cardiovascular events, and hospitalization. N Engl J Med 2004;351:1296-305

3. Sarnak MJ, Levey AS, Schoolwerth AC, Coresh J, Culleton B, Hamm LL, et al. Kidney disease as a risk factor for development of cardiovascular disease: a statement from the American Heart Association Councils on Kidney in Cardiovascular Disease, High Blood Pressure Research, Clinical Cardiology, and Epidemiology and Prevention. Circulation 2003;108:2154-69

4. American Diabetes Association. Standards of medical care in diabetes. Diabetes Care 2013;36:11-66

5. UK CKD guidelines consultation draft 9th December 2005. Available at http://www.kidney.org.uk/main/guidelines/UK_CKD_ guidelines_consultation_draft.pdf

6. Cumming A, Payne S. The renal system. In Doglas G, Nicol F \& Robertson C. Macleod's Clinical Examination. 12th International ed. Churchill 
Livingstone Elsevier;2009:223-224

7. International Diabetes Federation, 2012 Clinical Guidelines Task Force Global Guideline for Type 2 Diabetes. Available at: http://www.societatediabet.ro/pdf/Global-Guideline-for-Type-2-DiabetesIDF-2012.pdf

8. Levey AS, Coresh J, Balk E, Kausz AT, Levin A, Steffes MW et al. National Kidney Foundation Practice Guidelines for Chronic Kidney Disease: Evaluation, Classification, and Stratification. Ann Intern Med 2003; 139:137-147

9. NICE clinical guidelines. CG73 Chronic kidney disease. Early identification and management of chronic kidney disease in adults in primary and secondary care. Issued: September 2008. Available at http://publications.nice.org.uk/chronic-kidney-disease$\operatorname{cg} 73$

10. Levin A, Hemmelgarn B, Culleton B, Tobe S, McFarlane P, Ruzicka M, et al. Guidelines for the management of chronic kidney disease. CMAJ 2008; 179:1154-62

11. Keane WF, Eknoyan G. Proteinuria, albuminuria, risk, assessment, detection, elimination (PARADE): a position paper of the National Kidney Foundation. Am J Kidney Dis 1999;33:1004-10

12. Beetham R, Cattell WR. Proteinuria: pathophysiology, significance and recommendations for measurement in clinical practice. Ann Clin Biochem 1993;30:425-34

13. National Kidney Foundation. K/DOQI Clinical Practice Guidelines and Clinical Practice Recommendations for Diabetes and Chronic Kidney Disease. Am J Kidney Dis. 2007;49(2 suppl 2):S1-179. Available at http://www.kidney.org/professionals/KDOQI/guideline _diabetes

14. Molitch ME, DeFronzo RA, Franz MJ, Keane WF, Mogensen CE, Parving $\mathrm{HH}$, et al. Nephropathy in Diabetes. (American Diabetes Association Position Statement). Diabetes Care. 2004;27:79-83

15. Canadian Diabetes Association Clinical Practice Guidelines Expert Committee. Canadian Diabetes Association 2008 clinical practice guidelines for the prevention and management of diabetes in Canada. Can J Diabetes 2008;32:95-S98.Available at http://www.diabetes.ca

16. Scottish Intercollegiate Guidelines Network. Management of diabetes. A national clinical guideline. March 2010. Available at http://www.sign.ac.uk/pdf/sign116.pdf

17. The National Collaborating Centre for Chronic Conditions. Type 2 diabetes: the management of type 2 diabetes. NICE clinical guideline 87. London: Royal College of Physicians; 2009. Available at http://www.nice.org.uk/nicemedia/pdf/CG87NICEGui deline.pdf

18. Chadban S, Howell M, Twigg S, Thomas M, Jerums G, Alan C, et al. National evidence based guideline for diagnosis, prevention and management of chronic kidney disease in type 2 diabetes. Canberra: Diabetes Australia and the NHMRC;2009

19. National Kidney Foundation. K/DOQI clinical practice guidelines for chronic kidney disease: evaluation, classification, and stratification. Am J Kidney Dis 2002;39:1-266

20. Davies DF, Shock NW. Age changes in glomerular filtration rate, effective renal plasma flow, and tubular excretory capacity in adult males. J Clin Invest. 1950; 29:496-507

21. Lindeman RD, Tobin J, Shock NW. Longitudinal studies on the rate of decline in renal function with age. J Am Geriatr Soc. 1985; 33:278-85

22. Rowe JW, Andres R, Tobin JD, Norris AH, Shock NW. The effect of age on creatinine clearance in men: a cross-sectional and longitudinal study. J Gerontol. 1976; 31:155-63

23. Snively SC and Gutierrez C. Chronic Kidney Disease: Prevention and Treatment of Common Complications. Am Fam Physician. 2004 Nov 15;70:1921-1928

24. Scottish Intercollegiate Guidelines Network. Management of diabetes. A national clinical guideline. March 2010. Available at http://www.sign.ac.uk/pdf/sign116.pdf

25. Ruggenenti P, Perna A, Gherardi G, Garini G, Zoccali C, Salvadori M, et al. Renoprotective properties of ACE-inhibition in non-diabetic nephropathies with nonnephrotic proteinuria. Lancet 1999;354:359-64

26. The ACE Inhibitors in Diabetic Nephropathy Trialist Group. Should all patients with type 1 diabetes mellitus and microalbuminuria receive angiotensin-converting enzyme inhibitors: a meta-analysis of individual patient data. Ann Intern Med 2001;134:370-379

27. Parving HH, Lehnert H, Brochner-Mortensen J, Gomis $\mathrm{R}$, Andersen S, Arner P. The effect of irbesartan on the development of diabetic nephropathy in patients with type 2 diabetes. N Engl J Med 2001;345:870-8

28. Lewis EJ, Hunsicker LG, Clarke WR, Berl T, Pohl MA, Lewis JB, et al: Renoprotective effect of the angiotensin-receptor antagonist irbesartan in patients with nephropathy due to type 2 diabetes. N Engl J Med 2001 Sep 20;345:851-86

29. Brenner BM, Cooper ME, de Zeeuw D, Keane WF, Mitch WE, Parving HH, et al. Effects of losartan on renal and cardiovascular outcomes in patients with type 2 diabetes and nephropathy. $\mathrm{N}$ Engl J Med 2001;345:861-9

30. The ACE Inhibitors in Diabetic Nephropathy Trialist Group. Should all patients with type 1 diabetes mellitus and microalbuminuria receive angiotensin-converting enzyme inhibitors: a meta-analysis of individual patient data. Ann Intern Med 2001;134:370-379

31. Strippoli GFM, Bonifati C, Craig M, Navaneethan SD, Craig JC. Angiotensin converting enzyme inhibitors and angiotensin II receptor antagonists for preventing 
the progression of diabetic kidney disease (Cochrane Review). In: The Cochrane Library, Issue 4, 2006. London: Wiley.

32. Diabetes Control and Complications Trial Research Group: The effect of intensive treatment of diabetes on the development and progression of long-term complications in insulin-dependent diabetes mellitus. $\mathrm{N}$ Engl J Med 1993;329:977-986

33. UK Prospective Diabetes Study Group: Intensive blood glucose control with sulphonylureas or insulin compared with conventional treatment and risk of complications in patients with type 2 diabetes (UKPDS 33). Lancet 1998;352:837-853

34. Mogensen CE, Neldam S, Tikkanen I, Oren S, Viskoper R, Watts RW, et al. Randomised controlled trial of dual blockade of the renin-angiotensin system in patients with hypertension, microalbuminuria, and non-insulin dependent diabetes: the Candesartan and Lisinopril Microalbuminuria (CALM) study. BMJ 2000;321:1440-4

35. Peterson JC, Adler S, Burkart JM, Greene T, Hebert LA, Hunsicker LG, et al. Blood pressure control, proteinuria, and the progression of renal disease. The Modification of Diet in Renal Disease Study. Ann Intern Med. 1995;123:754-62

36. Kasiske BL, Kalil RS, Ma JZ, Liao M, Keane WF. Effect of antihypertensive therapy on the kidney in patients with diabetes: a meta-regression analysis. Ann Intern Med.1993;118:129-38

37. Ruggenenti P, Perna A, Gherardi G, Gaspari F, Benini $\mathrm{R}$, Remuzzi G, et al. Renal function and requirement for dialysis in chronic nephropathy patients on longterm ramipril: REIN follow-up trial. Gruppo Italiano di Studi Epidemiologici in Nefrologia (GISEN). Ramipril Efficacy in Nephropathy. Lancet. 1998;352:1252-6

38. Viberti G, Wheeldon NM, MicroAlbuminuria Reduction with VALsartan (MARVAL) Study Investigators. Micro-albuminuria reduction with valsartan in patients with type 2 diabetes mellitus: a blood pressure-independent effect. Circulation.2002;106:672-8

39. Siebenhofer A, Plank J, Horvath K, Berghold A, Sutton AJ, Sommer R, et al. Angiotensin receptor blockers as anti-hypertensive treatment for patients with diabetes mellitus; meta-analysis of controlled double-blind randomized trials. Diabet Med.2004;21:18-25

40. Praga M, Andrade CF, Luno J, Arias M, Poveda R, Mora J, et al. Antiproteinuric efficacy of losartan in comparison with amlodipine in non-diabetic proteinuric renal diseases: a double-blind, randomized clinical trial. Nephrol Dial Transplant.2003;18:1806-13

41. Brenner BM, Cooper Me, de Zeeuw D, Keane WF, Mitch WE, Parving HH, et al. Effects of losartan on renal and cardiovascular outcomes in patients with type 2 diabetes and nephropathy. $\mathrm{N}$ Engl J Med.2001;345:861-9

42. Levey AS. Clinical practice. Nondiabetic kidney disease. N Engl J Med 2002;347:1505-11

43. GISEN Group (Gruppo Italiano di Studi Epidemiologici in Nefrologia). Randomised placebocontrolled trial of effect of ramipril on decline in glomerular filtration rate and risk of terminal renal failure in proteinuric, non-diabetic nephropathy. Lancet 1997;349:1857-63

44. Ruggenenti P, Perna A, Gherardi G, et al. Renal function and requirement for dialysis in chronic nephropathy patients on long-term ramipril: REIN follow-up trial. Gruppo Italiano di Studi Epidemiologici in Nefrologia (GISEN). Ramipril efficacy in nephropathy. Lancet 1998;352:1252-6

45. Hansen HP, Tauber-Lassen E, Jensen BR, Parving HH. Effect of dietary protein restriction on prognosis in patients with diabetic nephropathy. Kidney Int 2002;62:220-228

46. Kasiske BL, Lakatua JD, Ma JZ, Louis TA. A metaanalysis of the effects of dietary protein restriction on the rate of decline in renal function. Am J Kidney Dis 1998;31:954-961

47. Garg JP, Bakris GL. Microalbuminuria: marker of vascular dysfunction, risk factor for cardiovascular disease. Vasc Med 2002; 7:35-43

48. Kasiske BL. Hyperlipidemia in patients with chronic renal disease. Am J Kidney Dis 1998;32(Suppl 3):S142-56

49. Orth SR, Stockmann A, Conradt C, Ritz E, Ferro M, Kreusser W, et al. Smoking as a risk factor for endstage renal failure in men with primary renal disease. Kidney Int.1998;54:926-31

50. Gall MA, Hougaard P, Borch-Johnsen K, Parving HH. Risk factors for development of incipient and overt diabetic nephropathy in patients with non-insulin dependent diabetes mellitus: prospective, observational study. BMJ 1997;314:783-788 